\title{
The N-terminal 1-16 peptide derived in vivo from protein seminal vesicle protein IV modulates $\alpha$-thrombin activity: potential clinical implications
}

\author{
Marilena Lepretti ${ }^{1}$, Susan Costantini ${ }^{2,3}$, \\ Gaetano Ammirato ${ }^{1}$, Gaia Giuberti ${ }^{1}$, \\ Michele Caraglia ${ }^{1,6}$, Angelo M. Facchiano ${ }^{2,3}$, \\ Salvatore Metafora ${ }^{5}$ and Paola Stiuso ${ }^{1,6}$ \\ ${ }^{1}$ Dipartimento di Biochimica e Biofisica \\ Seconda Università degli Studi di Napoli, \\ Vico L. De Crecchio 7, 80138 Naples, Italy \\ ${ }^{2}$ Laboratorio di Bioinformatica e Biologia Computazionale \\ Istituto di Scienze dell'Alimentazione, \\ CNR Via Roma 52 A/C, 83100 Avellino, Italy \\ ${ }^{3}$ Centro di Ricerca Interdipartimentale di Scienze \\ Computazionali e Biotecnologiche (CRISCEB) \\ Seconda Università degli Studi di Napoli \\ Via Costantinopoli 16, 80138 Naples, Italy \\ ${ }^{6}$ Corresponding authors: Tel, 39-081-5667577; Fax, 39-081-5665863; \\ E-mail, paola.stiuso@ unina2.it (P. Stiuso) and \\ Tel, 39-081-5665871; FAX, 39-081-5665863; \\ E-mail: michele.caraglia@unina2.it (M. Caraglia) \\ DOI 10.3858/emm.2008.40.5.541
}

\section{Accepted 24 June 2008}

Abbreviations: AT, antithrombin III; CD, circular dichroism; PDB, Protein Data Bank; PPP, platelet-poor plasma; RP-HPLC, reversed-phase HPLC; RT, recalcification time; SV-IV, seminal vesicle protein no. 4

\begin{abstract}
We have previously shown that seminal vesicle protein IV (SV-IV) and its 1-70 N-terminal fragment have anti-inflammatory activity and modulate anti-thrombin III (AT) activity. Moreover, mass spectrometry analysis of purified SV-IV has shown that the protein was found to be highly heterogeneous and $14 \%$ of the total SV-IV molecules are truncated forms, of particular interest the 1-16, 1-17, and 1-18 peptides. In this work we report experimental data which demonstrate that the 1-16 peptide (P1-16) possesses a marked effect on the AT activity by preventing the formation of the thrombin-AT complex. We found that the formation of thrombin-AT complex is markedly decreased in the presence of P1-16 used at equimolar concentration with thrombin as evaluated with SDS-PAGE. We also monitored the
\end{abstract}

conformational changes of thrombin in the presence of different P1-16 concentrations, and calculated the $K_{d}$ of thrombin/P1-16 system by circular dichroism technique. The probable interaction sites of P1-16 with thrombin have been also evaluated by molecular graphics and computational analyses. These results have potential implications in the treatment of sterility and thrombotic diseases.

Keywords: blood coagulation; hemostasis; Svp4 protein; thrombin

\section{Introduction}

The coagulant activity of seminal plasma is due to the coexistence of the elements of hemostatic system (Lwaleed, 2004) and the HMW-SV (High Molecular Weight Seminal Vesicle) protein system. Our attention was focused on the SV-IV (seminal vesicle protein No. 4, according to its mobility in SDS/PAGE), a basic, thermostable, secretory protein of low MW (9758) synthesized by the rat seminal vesicle (SV) epithelium under strict androgen transcriptional control (Ostrowski, 1979; Mansson, 1981; Lwaleed, 2004). SV-IV has been purified to homogeneity and characterized extensively (Ostrowski, 1979; Mansson, 1981; Pan, 1982; Harris, 1983; Kandala, 1983; McDonald, 1983; Abrescia, 1985,1986; Metafora, 1987a; D'Ambrosio, 1993 Stiuso, 1999; Lwaleed, 2004). Proteins immunorelated by SV-IV have been found in several rat tissues (uterus, lung, liver, brain, etc.), in human seminal fluid and SV secretion (Abrescia, 1985, 1986; Metafora, 1987a). SV-IV possesses potent non-species specific immunomodulatory and antiinflammatory activities, and modulates the coagulation process by affecting the thrombin-antithrombin III (AT) interaction (Galdiero, 1989; Metafora, 1989a, b; Camussi, 1990; Romano-Carratelli 1993; Vuotto, 1993; Di Micco 1994, 1997, 2000; Peluso, 1994; Mancuso, 1996; Tufano, 1996). Moreover, it can bind the plasma membrane of epididymal spermatozoa, decreasing the immunogenicity of SV-IV (Pavonessa, 1984; Metafora, 1987b; Peluso, 1994). SV-IV exerts its modulatory effects on the immune response by interfering with the macrophage-T cell cooperation (interference with cytokine 
release and biological activity; inhibition of the macrophage antigen presentation activity; inhibition of the $\mathrm{T}$ lymphocyte activation process) (Galdiero, 1989; Metafora, 1989b; Vuotto, 1993; Romano-Carratelli 1993; Peluso, 1994; Tufano, 1996). We have previously shown with hydrolytic experiments that the modulating effect on the coagulation of the protein is located in its 1-70 $\mathrm{N}$-terminal fragment (Di Micco, 1994, 1997). Mass spectrometry analysis of purified SV-IV demonstrated that it is highly heterogeneous (Ferranti, 1997). Truncated forms of SV-IV are also present and represent about $14 \%$ of the total molecules, in detail the 1-16, 1-17, and 1-18 peptides derived from the $\mathrm{N}$-terminus of the protein. The processing mechanism leading to their formation could be related to the synergistic effects of chymotrypsinlike and carboxypeptidase enzymes (Ferranti, 1997).

In this paper we show that 1-16 peptide (P1-16) exerts a marked effect on the AT activity, by preventing the formation of the thrombin-AT complex. We have also monitored the effects of P1-16 on the thrombin conformation and evaluated the $K_{d}$ value for the thrombin/P1-16 system. On the evidence that the binding of $\mathrm{P} 1-16$ to thrombin affects the thrombin conformation and prevents the formation of thrombin-AT complex, we evaluated by molecular graphics and computational analyses the probable interaction sites.

\section{Materials and Methods}

\section{Purification of protein SV-IV and solid-phase peptide synthesis}

Milligram amounts $(600 \mathrm{mg})$ of protein SV-IV were purified to homogeneity from the seminal vesicle secretion of adult rats (Fisher-Wistar) according to a published procedure by using ion exchange and gel filtration column chromatography (Lwaleed, 2004). The purity of the protein was evaluated by SDS/PAGE in denaturing and non denaturing conditions (Abrescia, 1986). The concentration of the purified SV-IV was measured by its molar absorption at $276 \mathrm{~nm}\left(4,100 \mathrm{M}^{-1} \cdot \mathrm{cm}^{-1}\right)$, calculated on the basis of the tyrosine and phenylalanine residues present in the SV-IV polypeptide chain (Di Micco, 1994; Stiuso, 1999). Peptides were prepared by organic synthesis on solid-phase with a continuous-flow instrument with on-line UV monitoring (Milligen/Biosearch 9050) and purified by RP-HPLC using a previously published procedure (Ialenti, 2001).

\section{Preparation of platelet-poor plasma (PPP)}

PPP was prepared from the venous blood of young, healthy, non-smoking individuals. Following addition of $0.1 \mathrm{M}$ sodium citrate $(9: 1, \mathrm{v} / \mathrm{v})$, the blood samples were centrifuged at $3,000 \mathrm{~g}$ for $30 \mathrm{~min}$ at room temperature. The supernatant, containing 2-20 platelets $\cdot \mu l^{-1}$, was separated carefully from the pellet and immediately used as PPP in the experiments (Di Micco, 1994).

\section{Recalcification time (RT)}

The evaluation of the RT was carried out with a technique similar to Howell's original method (Di Micco, 1994), except that PPP was used instead of platelet-rich plasma. The test was performed at $37^{\circ} \mathrm{C}$ by mixing $0.1 \mathrm{ml} 30 \mathrm{mM} \mathrm{CaCl}_{2}$ with $0.1 \mathrm{ml}$ PPP in the presence of $0.1 \mathrm{ml}$ of either native SV-IV, SV-IV CNBr-fragments, synthesized SV-IV peptide derivatives at various equimolar concentrations or $150 \mathrm{mM} \mathrm{NaCl}$ (control) and recording the coagulation time. The RT was also evaluated by using PPP treated with a specific rabbit anti-AT polyclonal serum (anti-AT treated PPP; Sigma). In more detail, $200 \mu \mathrm{l}$ normal PPP was mixed with 50 $\mu \mathrm{L}$ anti-AT serum and the reaction mixture was incubated at $37^{\circ} \mathrm{C}$ for $10 \mathrm{~min}$ to allow specific antigen-antibody recognition to occur. At the end of the incubation, $0.1 \mathrm{ml}$ aliquots of the anti-ATtreated PPP were used in the RT assay to measure the coagulation time in the absence or in the presence of different concentrations of either SV-IV, SV-IV CNBr-fragments, or synthesized SV-IV peptide derivatives. In control experiments, where PPP was treated with a pool of normal rabbit sera, the SV-IV or SV-IV-derived peptides effect on RT was similar to that obtained with untreated PPP.

\section{Coagulation time of a purified clotting system}

The reaction mixture of the purified clotting system contained $300 \mu \mathrm{g}$ fibrinogen (Behring, Milan, Italy), $2.5 \mathrm{U}$ alpha-thrombin (Behring), and $0.2 \mathrm{U}$ heparin (Liquemin; Roche) in $0.3 \mathrm{ml} 150 \mathrm{mM} \mathrm{NaCl}$. Heparin was included in the mixture to activate the AT after its addition to the system. Where indicated, equimolar concentrations $(5 \mu \mathrm{M})$ of SV-IV, SV-IV CNBrfragments (1-70 and 71-90), or synthesized P1-16, and/or human purified AT (Sigma) were added to the reaction mixture to analyse their effect on the coagulation time of the system, accordingly to previously described methods (Di Micco, 1994, 1997). The reaction mixtures, in which coagulation was started by thrombin addition, were incubated at $37^{\circ} \mathrm{C}$ and the coagulation times were recorded. 


\section{Thrombin activity assay}

The coagulant activity of SV-IV or SV-IV-derived peptides was evaluated by assessing in vitro with a colorimetric kinetic assay the effect of these molecules on the thrombin activity in the presence of AT. The assay was performed by using the tosyl-gly pro-arg-p-nitroanilide (Chromozym, Boehringer Mannheim, Monza, Italy) as chromogenic substrate of the thrombin activity. The reaction mixture $(1 \mathrm{ml})$ contained $94 \mu \mathrm{M}$ Chromozym, 1.25 $\times 10^{-2} \mu \mathrm{M}$ thrombin (Sigma), $1.25 \times 10^{-2} \mu \mathrm{M}$ AT (Sigma), $50 \mathrm{mM}$ Tris/ $\mathrm{HCl} \mathrm{pH} 8.3,150 \mathrm{mM} \mathrm{NaCl}$, and different concentrations of P1-16. Absorbance (A) at $405 \mathrm{~nm}$ was measured every min for a total time of $30 \mathrm{~min}$. The thrombin activity was expressed as the change in absorbance at $450 \mathrm{~nm}$ produced per min by the enzyme from the chromogenic substrate Chromozym. $\Delta \mathrm{A}_{405} \cdot \mathrm{min}^{-1}$ was calculated as follows:

$$
\triangle A_{405} \cdot \min ^{-1}=\frac{\left(\sum \Delta A_{405} \cdot \min ^{-1}\right)}{30}
$$

where $\Sigma \Delta \mathrm{A}_{405} \cdot \mathrm{min}^{-1}$ is the sum of the different absorbance values, taken every minute at $405 \mathrm{~nm}$ for a total time of $30 \mathrm{~min}$, minus the absorbance at $405 \mathrm{~nm}$ taken immediately after addition of the chromogenic substrate to the reaction mixture; 30 represents the total duration (expressed in $\mathrm{min}$ ) of the thrombin-catalysed reaction.

\section{Preparation of thrombin-AT complex}

Thrombin-AT complexes were prepared incubating for 60 min alpha-thrombin $1 \mu \mathrm{M}$ with AT $10 \mu \mathrm{M}$ in $20 \mathrm{mM}$ Tris buffer, $\mathrm{pH} 7.4$ containing $0.1 \mu \mathrm{M} \mathrm{NaCl}$ and $0.1 \%$ poly (ethylene glycol) $\mathrm{Mr} 8000$, in the absence or presence of $1 \mu \mathrm{M}$ peptide 1-16. After $60 \mathrm{~min}$, the thrombin-AT complexes were analyzed by SDS-PAGE (Laemmli, 1970) under non-reducing conditions in a $10 \%$ gel system. For non-reducing conditions a normal SDS-PAGE was performed without the addition of reducing agents such as $\beta$-mercaptoethanol. The bands were detected with silver stain. At the same conditions, the autolysis of the thrombin in absence or in presence of $1 \mu \mathrm{M}$ peptide 1-16 was monitored at different incubation times $(0,20,30,40,50,60 \mathrm{~min})$.

\section{Equilibrium binding studies by $\mathrm{CD}$ experiments}

$\mathrm{CD}$ measurements were performed at $25^{\circ} \mathrm{C}$ with a Jasco J-720 spectropolarimeter, using quartz cells with a $1 \mathrm{~cm}$ path length. The sample was continuously stirred to prevent the adsorption of the enzyme to cell surface. The CD spectra were analyzed in the region between 200 and $240 \mathrm{~nm}$ to evaluate the amount of secondary structure by using K2d program (http://www.imb-jena.de/lmgLibDoc/cd/indexsummary. htm).

The binding between thrombin and peptide 1-16 can be represented by the following equations:

$$
\begin{aligned}
& E+P=E P \\
& K_{d}=\frac{[E][P]}{[E P]}=\frac{k_{-1}}{k_{1}}
\end{aligned}
$$

where $[E],[P]$ represent the concentrations of the unbound thrombin and of peptide P1-16.

In terms of the total enzyme concentration $[E]_{0}$,

$[E P]=\frac{[E]_{0}[P]}{K_{d}}$

According to the analysis procedure suggested in literature (Fersht, 1985), the data have been analyzed by using the equivalent of the Eadie plot:

$[E P]=[E]_{0}-K_{d} \frac{[E P]}{[P]}$

By considering that $[E P]$ is usually directly proportional to the change in the spectroscopic signal, we have:

$\triangle \theta=\Delta \theta_{\max }-K_{d} \frac{\Delta \theta}{[P]}$

where $\Sigma \theta$ is the change in ellipticity when $[\mathrm{P}]$ is added to the protein solution. Therefore, the dissociation constant of the EP complex was calculated by variation of dichroic activity at $222 \mathrm{~nm}$ of thrombin with different concentrations of peptide. Leastsquares fitting and dissociation constant calculation were performed with GRAPH Pad software.

\section{Molecular graphics and computational analyses}

The molecular structures of human thrombin complexed with human AT (PDB code: 1TB6) (Li, 2004) and human fibrinopeptide (PDB code: $1 \mathrm{FPH}$ ) (Stubbs, 1992) were selected from the PDB web site (http://www.rcsb.org/pdb/).

The "Protein - Protein Interaction Server" (http:// www.biochem.ucl.ac.uk/bsm/PP/server/) and the NACCESS program (http://wolf.bms.umist.ac.uk/ naccess/) were used to identify thrombin amino acids involved in the interaction with AT and fibrinopeptide. Secondary structure was assigned with DSSP program (Kabsch, 1983). The SURFNET program (Laskowski, 1995) was used in order to 
locate and visualize the surfaces and the cavities of thrombin in two complexes. Model figures were drawn with Insightll package (Accelrys, San Diego, CA).

\section{Results}

\section{Effect of P1-16 on AT inhibition of thrombin}

The coagulant properties of the native SV-IV are clearly indicated in previously published data (Di Micco, 1994, 1997, 2000). In Table 1, we report the evaluation of recalcification time (RT) by using platelet poor plasma (PPP) in the absence (untreated) and in the presence of anti-AT polyclonal serum, with addition of SV-IV or its peptide derivatives. Both P1-16 and P1-70 act, similarly to SV-IV, by reducing RT in the presence of AT. Similarly, the coagulation time of a purified clotting system decreased after addition of P1-16, P1-70, or SV-IV in the presence of AT. In Figure $1 \mathrm{~A}$ we report the thrombin activity assay (see Methods). The presence of AT strongly reduced thrombin activity, but the simultaneous addition of AT and P1-16 did not affect enzyme activity.

P1-16 did not antagonize the formation of covalent complexes between thrombin and AT. In fact, AT activity was totally inhibited if thrombin was pre-incubated for $10 \mathrm{~min}$ with AT (ratio 1:1), (see Figure 1B). Moreover, we have evaluated by non-reducing SDS-PAGE analysis whether P1-16 affected both detection and formation of the thrombin-AT complex (Figure 2, panel A). Alpha thrombin was loaded in lane 1 . The arrow shows

Table 1. Effects of SV-IV, P1-70, P70-90 and P1-16 $(5 \mu \mathrm{M})$ on PPP recalcification time. And coagulation time of a purified clotting system.

\begin{tabular}{|c|c|c|c|c|}
\hline \multirow{2}{*}{ Addition } & \multicolumn{2}{|c|}{ Recalcification time (s) } & \multicolumn{2}{|c|}{$\begin{array}{l}\text { Coagulation time (s) } \\
\text { (fibrinogen/thrombin/heparin coagulation system) }\end{array}$} \\
\hline & Untreated PPP & Anti-AT treated PPP & -ATIII & +ATIII \\
\hline None (control) & $200 \pm 14$ & $67 \pm 6$ & $51 \pm 3$ & $200 \pm 10$ \\
\hline SV-IV & $68 \pm 6^{*}$ & $70 \pm 4$ & $53 \pm 4$ & $52 \pm 5^{\star *}$ \\
\hline P1-70 & $71 \pm 7^{*}$ & $72 \pm 8$ & $52 \pm 2$ & $51 \pm 4^{* *}$ \\
\hline P71-90 & $205 \pm 13$ & $69 \pm 5$ & $54 \pm 6$ & $172 \pm 9$ \\
\hline P1-16 & $65 \pm 3^{*}$ & $69 \pm 2$ & $52 \pm 4$ & $50 \pm 3^{\star *}$ \\
\hline
\end{tabular}

The values reported in the table are the means \pm SEM of six determinations performed in triplicate. ${ }^{*} P<0.01$ if compared to untreated PPP control, Student's $t$-test for paired data; ${ }^{* *} P<0.01$ if compared to + ATIII control, Student's $t$-test for paired data.

A

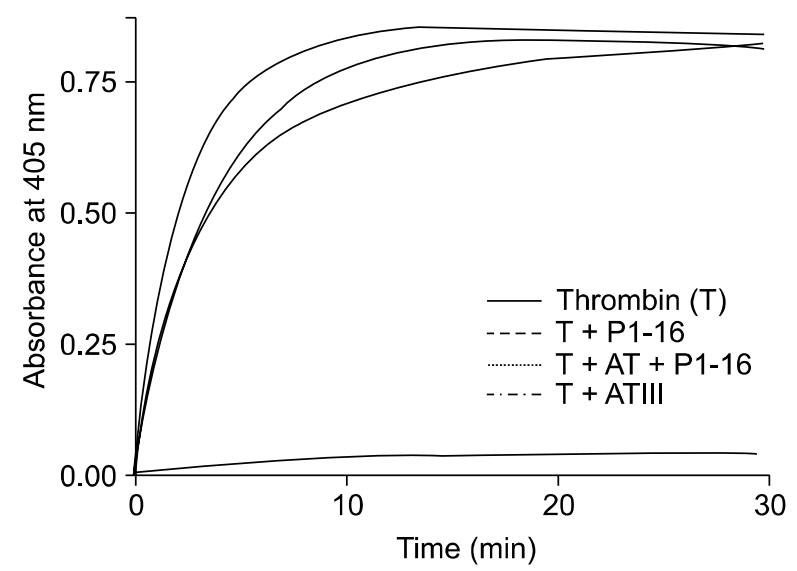

B

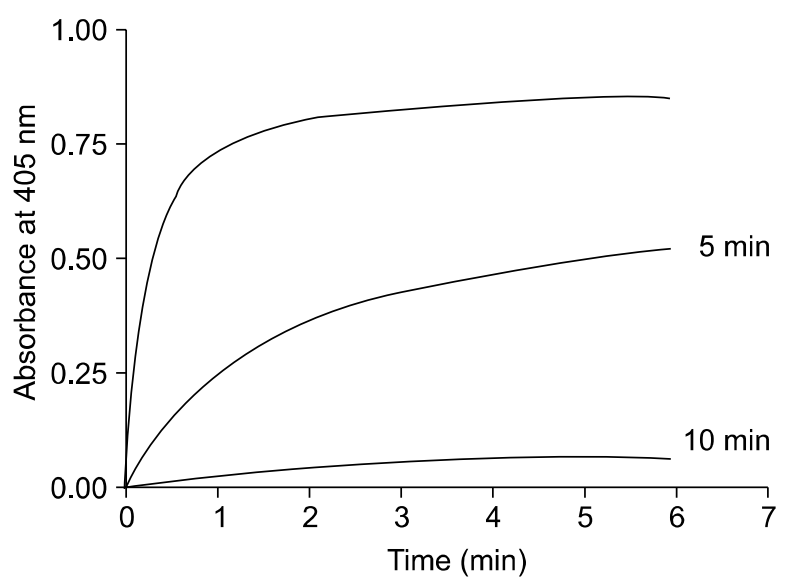

Figure 1. Effect of P1-16 on the thrombin activity in presence or in absence of AT. (A) The activity of thrombin (1 $\mu \mathrm{M})$, evaluated with a colorimetric kinetic assay, was expressed as optical density at $405 \mathrm{~nm}$ produced by enzyme from a chromogenic substrate (Chromozym $94 \mu \mathrm{M})$. Further experimental details are reported in Materials and Methods. (B). The activity of the thrombin was monitored after 5 and 10 min of pre-incubation with AT, followed by the addition of P1-16. The dashed line represents the control of the activity of alpha-thrombin. 
the $37 \mathrm{kDa}$ molecular weight marker. The mixture of alpha thrombin and AT (molar ratio 1:10) incubated for $60 \mathrm{~min}$ was loaded in lane 2. In this experimental conditions, alpha thrombin completely reacted with AT and no band at $37 \mathrm{kDa}$ was detectable. Mixtures of thrombin and AT with 1 and $10 \mu \mathrm{M}$ P1-16 incubated for $60 \mathrm{~min}$ were loaded in lane 3 and 4 , respectively. The band at $37 \mathrm{kDa}$ demonstrates that the presence of $\mathrm{P} 1-16$ prevented the formation of the thrombin-AT complex. At the same time, P1-16 favoured the autolysis of thrombin, as shown by the increasing intensity of the low molecular weight thrombin band. In fact, it is known that the autolysis of thrombin forms two additional low molecular weight bands, corresponding to beta and gamma thrombin (Olson, 1993). In Figure 2, panel $B$, we report the result of the autolysis of thrombin. The effect of P1-16 on the autolysis of thrombin was confirmed by the incubation of thrombin in absence and presence of

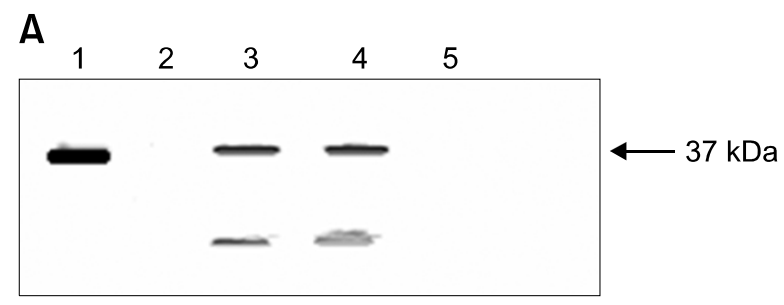

B

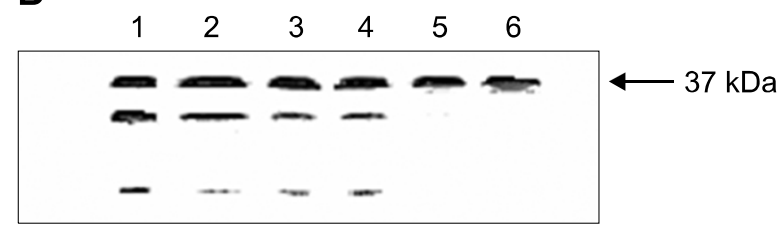

C

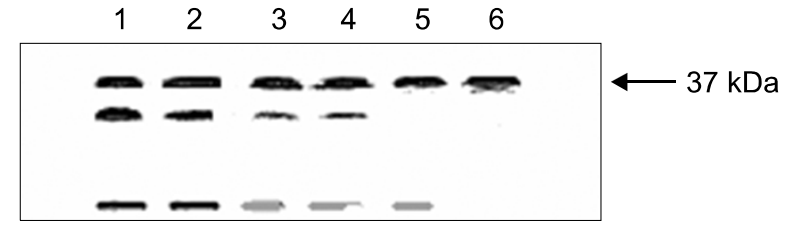

Figure 2. Non-reducing SDS-PAGE of the alpha-thrombin in presence of ATIll and/or P1-16. For nonreducing SDS-PAGE the samples were mixed with buffer without $\beta$-mercaptoethanol, and resolved on $10 \%$ SDS-polyacrylamide gels. (A) Lane 1: alpha-thrombin $(1 \mu \mathrm{M})$, lane 2: residual free alpha-thrombin after 60 min incubation time with AT $(10 \mu \mathrm{M})$; lane 3: residual free alpha-thrombin after 60 min incubation time with AT in presence of $1 \mu \mathrm{M}$ P1-16; lane 4: same conditions as in lane 3 but with $10 \mu \mathrm{M}$ of the P1-16. All the samples were reacted for $60 \mathrm{~min}$ in the buffer $\mathrm{pH}$ 7.4 at $25^{\circ} \mathrm{C}$ (see methods). Lane 5: AT $(10 \mu \mathrm{M})$. (B) Autolysis of the thrombin $(1 \mu \mathrm{M})$ after different incubation time (lane 1,2,3,4,5,6 are at $60,50,40,30,20,0 \mathrm{~min}$, respectively). (C) Autolysis of the thrombin (1 $\mu \mathrm{M})$ in presence of $1 \mu \mathrm{M}$ P1-16 at same times of $B$. equimolar amount of P1-16 (Figure 2, panel C).

\section{Equilibrium binding studies}

CD spectra reported in Figure 3 show that modifications of the thrombin structure occurred in the presence of $\mathrm{P} 1-16$ at two different concentrations. The far-UV CD spectra, as characterized by an isodichroic point located at about $208 \mathrm{~nm}$ indicated the presence of two-state equilibrium between the free alpha-thrombin and bound thrombin-P1-16 forms. The association process was accompanied by changes of the secondary structure. In detail, a $19 \%$ alpha helix and a $29 \%$ beta structure content was detected for free alpha-thrombin, whereas the

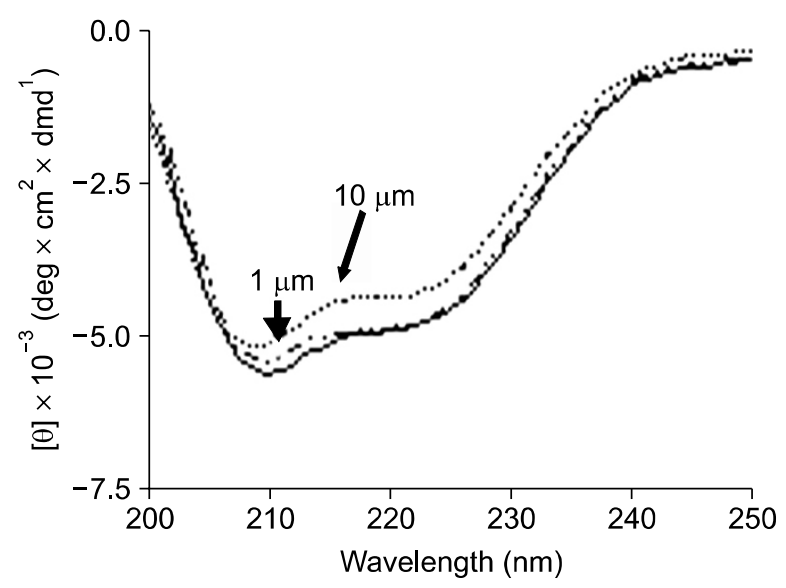

Figure 3. Structural change of thrombin in presence of P1-16. CD spectrum of $0.5 \mu \mathrm{M}$ thrombin in the far-UV region $(-)$. All spectra were recorded at $25^{\circ} \mathrm{C}$ in $10 \mathrm{mM}$ Tris- $\mathrm{HCl}$ buffer $\mathrm{pH} 8.0$, containing $0.1 \%$ PEG-8000, in the presence of 1 (..-..) and $10 \mu \mathrm{M}$ (---.) P1-16. The samples were continuously stirred to prevent the absorption of the enzyme to cell surface.

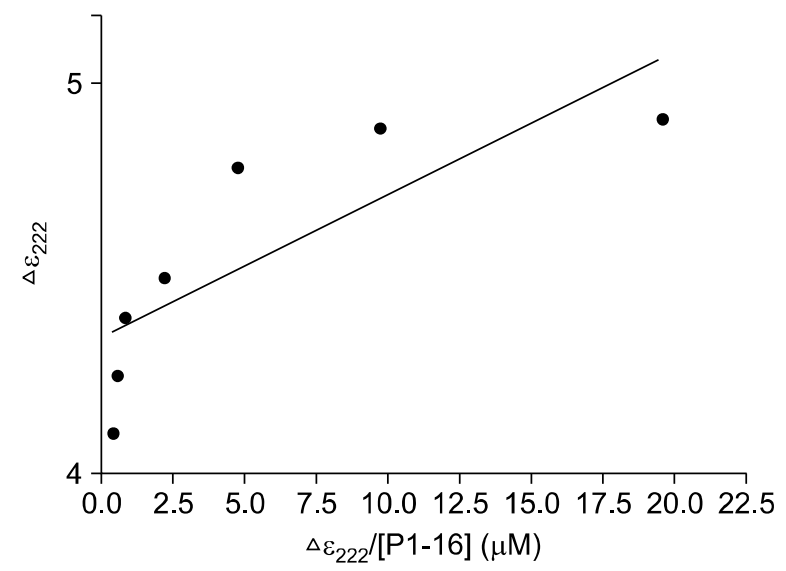

Figure 4. The Eadie plot. $\Delta \varepsilon_{222}$ is the change at $222 \mathrm{~nm}$ in the $\mathrm{CD}$ signal when different concentration of [P1-16] was added to the alpha-thrombin solution $(0.5 \mu \mathrm{M})$. 
alpha helix content was significantly lower, about $16 \%$, for bound thrombin-P1-16 (thrombin $0.5 \mu \mathrm{M}$ and P1-16 $10 \mu \mathrm{M})$. The analysis of CD spectra agreed with thrombin secondary structure derived from X-rays studies. However, some differences with previously published CD spectra were also found (De Filippis, 2005). Although the current secondary structure estimation methods are not able to quantify such subtle differences (Kelly, 2005), the evident change in ellipticity suggests that the binding of P1-16 affected the conformation of thrombin. The change of ellipticity intensity at $222 \mathrm{~nm}$ is plotted in Figure 4. This plot was used to determine the dissociation constant between thrombin and P1-16 (see Methods). The $K_{d}$ value was $0.073 \mu \mathrm{M}$.

The spectroscopic structural change of alphathrombin in the presence of different P1-16 concentrations was performed also by second derivative of absorbance spectra (data not shown). The structural transition obtained was superimposable with data derived from CD.

\section{Analysis of thrombin surface regions involved into protein-protein interaction and possible P1-16 binding sites}

We analysed by molecular graphics and computational methods the 3D structure of thrombin in order to predict the possible P1-16 binding sites. The sequence of the $\mathrm{P} 1-16$ peptide, i.e. $(\mathrm{NH} 3+) \mathrm{R}(+) \mathrm{K}(+) \mathrm{TK}(+) \mathrm{E}(-) \mathrm{K}(+) \mathrm{YSQSE}(-) \mathrm{E}(-) \mathrm{VVSE}(-$ )$S(C O O-)$, suggested that its binding site on the thrombin surface should expose a number of charged side chains, able to interact with both the five positive charges on the $\mathrm{N}$-terminal side and the four negative charges on the C-terminal side of the peptide. Moreover, the experimental results concerning the ability of $\mathrm{P} 1-16$ to prevent the formation of thrombin-AT complex, but not that of the thrombin-fibrinopeptide complex (Di Micco et al., manuscript in preparation), suggested that $\mathrm{P} 1-16$ could bind thrombin in a surface region involved in the interaction with AT but not with the fibrinopeptide. To investigate the features of thrombin surface and make some hypotheses about the

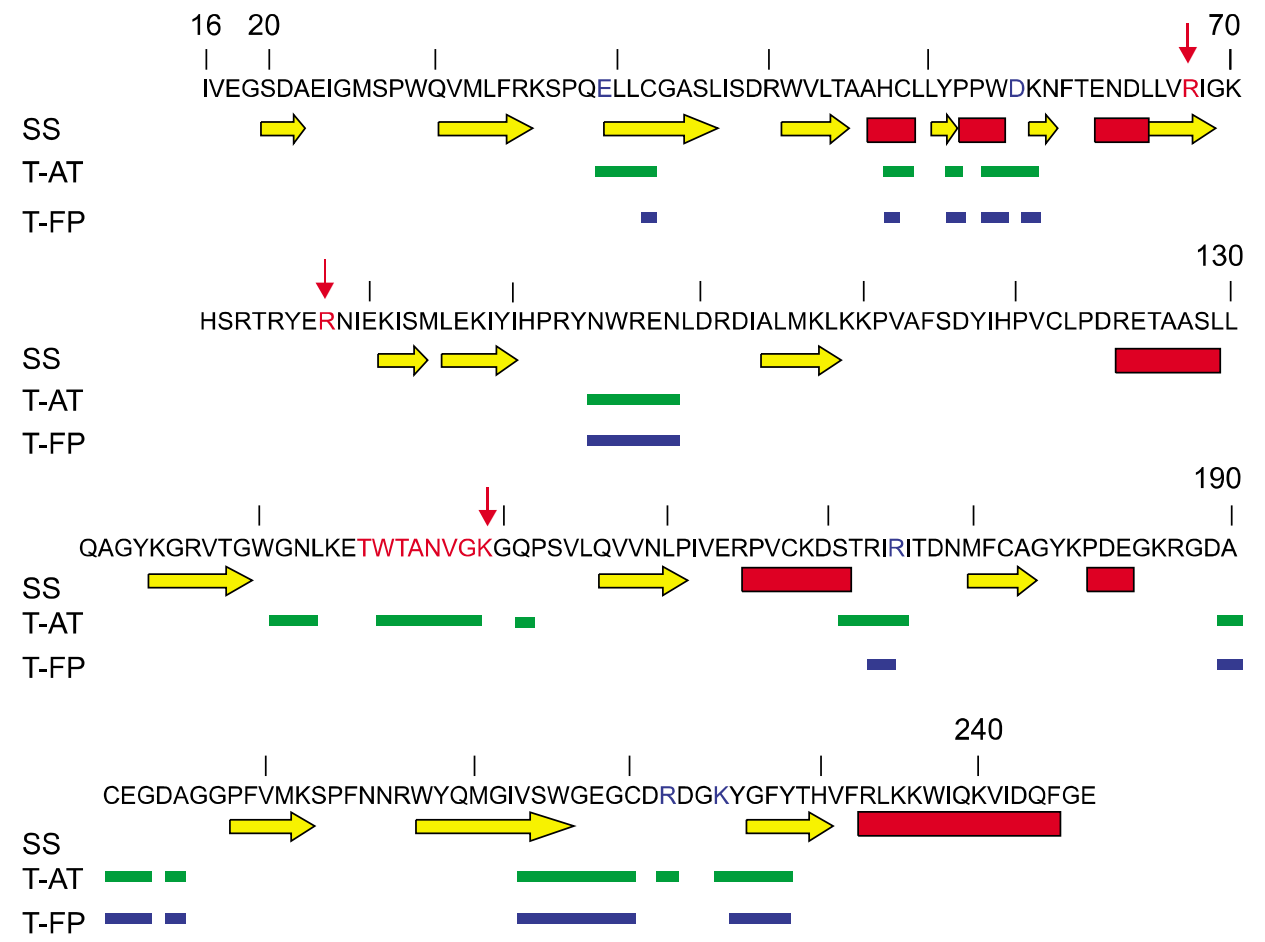

Figure 5. Amino acid sequence of thrombin with highlighted regions of interest for interaction with P1-16. The first row reports the amino acid sequence. Positions of amino acids are indicated according to the numeration in PDB structures, where some regions are numbered with letters (as an example, $60 \mathrm{~A}, 60 \mathrm{~B}$, and so on); for this reason, the number of amino acids does not correspond to the numeration reported. The cleavage sites for the formation of beta-thrombin (i.e. Arg77A) and gamma-thrombin (i.e. Arg67 and gamma-loop) are reported in red and indicated with arrows. The second row reports secondary structure elements (yellow arrows: beta strands; red bars: alpha helices) assigned with the DSSP program. Third and fourth rows indicate the amino acids which interact with AT in the T-AT complex (PDB file: 1TB6) and with fibrinopeptide in the T-FP complex (PDB file: 1FPH), with green and blue bars, respectively. The charged amino acids in these regions (i.e. Glu 39, Asp 60E, Arg 175, Arg 221A, Lys 224) are evidenced in blue. 
possible binding site, we evaluated the amino acid residues of thrombin involved in the interaction with AT and fibrinopeptide and their surface environment. Therefore, we analyzed with computational tools (for details, see Methods) the thrombin/AT (PDB code: 1TB6) and thrombin/fibrinopeptide (PDB code: 1FPH) complexes. In Figure 5 we have reported the thrombin amino acid sequence and highlighted regions involved into the interaction with AT and fibrinopeptide. Secondary structure elements and cleavage sites for the formation of beta- and gamma-thrombin are also shown. Being P1-16 able to affect the interaction with AT but not with the fibrinopeptide, we searched for putative P1-16 binding sites as regions involved only in the interaction with AT. By considering the distance among these sequence regions, and the need of charged residues to interact with charges on P1-16, we have found three putative binding sites surrounding the following residues: i) Glu 39 and Asp 60E; ii) Arg 175; iii) Arg 221A and Lys 224. These selected regions included the two exosites critical for stabilizing thrombin complex with AT: gamma-loop and the $\mathrm{Na}+$-binding site (Fersht, 1985). The gamma-loop (residues 147,147a, 147b, 147c, 147d, 147e, 148 and 149) (in Figure 5, evidenced in red), with its bulk would limit access to the active site cleft and can play a role in mediating contacts with other substrates. The second exosite involved two residues of thrombin, Arg 221A and Lys 224 (in Figure 5, both evidenced in red at the C-terminal region of thrombin sequence), that coordinate $\mathrm{Na}+$ along with some water molecules. The detailed features of these three regions are discussed below.

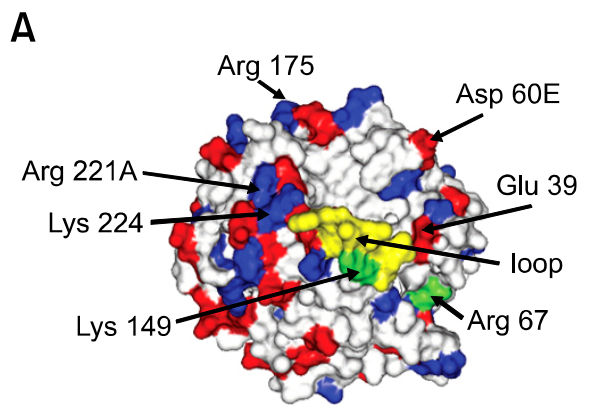

\section{Discussion}

The analysis of thrombin CD spectra evidenced a secondary structure very similar to that derived from the analysis of its structure at X-rays. However, our CD spectra data are different from those previously published (De Filippis, 2005). A possible explanation of $C D$ spectra alteration can be given by the tendency of thrombin to adhere to the cell wall (Latello, 1986). For this reason, we recorded $C D$ spectra using low concentrations of the enzyme and stirring the solution continuously. The agreement with the X-rays data confirms that this procedure can be considered effective to preserve the reliability of the thrombin CD spectra. Moreover, in our studies we have found that the peptide 1-16 possessed all the SV-IV coagulant activity and a marked effect on the thrombin-AT complex formations. By considering the high content of charged residues in P1-16, such effect may be due to ionic strength interaction between the alphathrombin and $\mathrm{P} 1-16$ with a dissociation constant of about $0.073 \mu \mathrm{M}$. The interaction induced a conformational change in the thrombin, and it could also cause the exposure of the autolysis loop, with the consequent increase in gamma- thrombin production. This hypothesis, based on our experimental data, has been evaluated by computational study. We analyzed in more detail the surface features around the possible binding sites, in particular for the presence of charged residues, secondary structure elements, and cavities (see Figures 5 and 6 ). The surface analysis for the presence of cavities indicates that the most relevant was located close to Glu39 and Asp60E sites. These observations suggest that these sites could

\section{B}

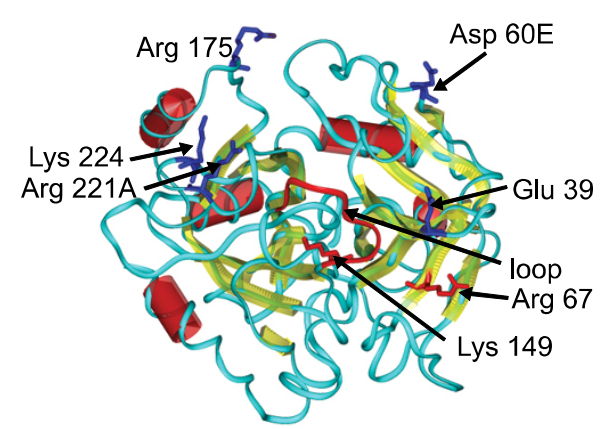

Figure 6. Detailed view of the thrombin surface. (A) Colours evidence the presence of negatively charged (red) and positively charged side chains (blue). The charged amino acids in three possible sites (i.e. Glu 39, Asp 60E, Arg 175, Arg 221A, Lys 224) are indicated by arrows. Sites of hydrolysis which generate gamma-thrombin (i.e. Arg67, Lys149) are evidenced in green. The gamma-loop is in yellow. (B)The backbone ribbon of thrombin structure and the secondary structure topology are shown: yellow arrows represent beta strands, red cylinders represent helices. Blue sticks indicate the charged amino acids in three possible sites (i.e. Glu 39, Asp 60E, Arg 175, Arg 221A, Lys 224). Sites of hydrolysis which generate gamma-thrombin (i.e. Arg67, Lys149) are evidenced in red sticks. The gamma-loop is reported in red. 
be responsible for the binding of P1-16 to thrombin. Arg175, Glu39 and Asp60E regions are all placed closely to helix regions, the alpha helix 165-171 and the 60B-60D helix $33_{10}$, respectively. A conformational change of these helix regions after the binding of P1-16 could explain the decrease of helix content observed by CD spectra after peptide binding. Moreover, Glu39 and Asp60E regions are near the gamma loop, which is cleaved at Lys 149 level to generate gamma-thrombin, while Arg175 region is distant. The binding of $\mathrm{P} 1-16$ increases the autolysis of thrombin to release gammathrombin (see also Figure 2, panel B and C). On the basis of these results, the possible effect of the binding of P1-16 on the accessibility of the gamma loop is matter of discussion. In fact, the binding of $\mathrm{P} 1-16$ to this region could prevent the autolysis for steric reasons. On the other hand, the increase of autolysis activity could not be explained by the binding of $\mathrm{P} 1-16$ to a remote region.

Concerning the third proposed site, Arg221A and Lys224 are both close to gamma loop, but are between two beta strands and far from helices.

In conclusion, we report the experimental evidence of the interaction of P1-16 with thrombin and its capability to modulate its activity by increasing the free thrombin availability by preventing the formation of thrombin-AT complex, as well as by improving the autolysis activity. This finding suggests a physiological role of $\mathrm{P} 1-16$ in the homeostatic control. It was reported that the semen contains a thrombin-like enzyme, prothrombin fragments 1 and $2(F 1+2)$, D-dimer (DD) and thrombin-AT (TAT) complexes as well as the seminal vesicle proteins (Ferranti, 1997). These proteins may have roles in seminal clotting and in liquefaction through "fibrinolytic" activity, which may ultimately affect fertility. Our data could be useful in order to design by a computer-based manner specific peptidemimetic inhibitor of the thrombin-AT binding in order to improve seminal clotting and fertility. On the other hand, small molecules favouring thrombin will be also screened in order to be used in haemorragic affections. Finally, by probing the activity of P1-16 on thrombin autolysis and thrombin-AT complex formation, our results contribute to elucidate the physiological in vivo role of this peptide.

\section{Acknowledgements}

PhD fellowships of ML, GA and SC were supported by E.U.

\section{References}

Abrescia P, Corbo L, Metafora S. Maturation in different translational systems of the protein RSV-IV secreted from the rat seminal vesicle epithelium. Bull Mol Bio Med 1986; 11:19-33

Abrescia P, Lombardi G, De Rosa M, Quagliozzi L, Guardiola $J$, Metafora S. Identification and preliminary characterization of a sperm-binding protein in normal human semen. J Reprod Fertil 1985;73:71-7

Camussi G, Tetta C, Bussolino F, Metafora S, Peluso G, Esposito C, Porta R. An anti-inflammatory protein secreted from the rat seminal vesicle epithelium inhibits the synthesis of platelet-activating factor and the release of arachidonic acid and prostacyclin. Eur J Biochem 1990;192:481-5

D'Ambrosio E, Del Grosso N, Ravagnan G, Peluso G, Metafora S. Cloning and expression of the rat genomic DNA sequence coding for the secreted form of the protein SV-IV. Bull Mol Biol Med 1993;18:215-23

De Filippis V, De Dea E, Lucatello F, Frasson R. Effect of Na+ binding on the conformation, stability and molecular recognition properties of thrombin. Biochem J 2005;390: 485-92

Di Micco B, Caen J, Colonna G, Macalello MA, Marchese M, Stiuso P, Di Micco P, Metafora S. Inhibition of antithrombin by protein SV-IV normalizes the coagulation of hemophilic blood. Eur J Pharmacol 2000;391:1-9

Di Micco B, Colonna G, Porta R, Metafora S. Rat protein SV-IV (seminal vesicle protein No. 4) accelerates human blood coagulation in vitro by selective inhibition of antithrombin III. Biochem Pharmacol 1994;48:345-52

Di Micco B, Stiuso P, Colonna G, Porta R, Marchese M, Schininà ME, Macalello MA, Metafora $S$. A peptide derivative (1-70 fragment) of protein SV-IV accelerates human blood coagulation in vitro by selective inhibition of the heparininduced antithrombin III activation process. J Pept Res 1997;49:174-82

Ferranti P, Mamone G, Malorni A, Guardiola J, Stiuso P, Metafora S. Structural heterogeneity, post-translational modifications, and biological activities of SV-IV, a major protein secreted from the rat seminal vesicle epithelium. Rapid Communic. In Mass Spectr 1997;11:1007-14

Fersht A. Enzyme structure and mechanism. Freeman W.H. and Company eds 1985, New York

Galdiero F, Tufano MA, De Martino L, Capasso C, Porta R, Ravagnan G, Peluso G, Metafora S. Inhibition of macrophage phagocytic activity by SV-IV, a major protein secreted from the rat seminal vesicle epithelium. J Reprod Immunol 1989;16:269-84

Harris SE, Mansson PE, Tully DB, Burkhart B. Seminal vesicle secretion IV gene, allelic difference due to a series of 20-base-pair direct tandem repeats within an intron. Proc Natl Acad Sci USA 1983;80:6460-4

lalenti A, Santagada V, Caliendo G, Severino B, Fiorino F, Maffia P, lanaro A, Morelli F, Di Micco B, Carteni M, Stiuso $P$, Metafora V, Metafora S. Synthesis of novel antiinflammatory peptides derived from the amino-acid sequence of the bioactive protein SV-IV. Eur J Biochem 2001;268:3399-406 
Kabsch W, Sander C. Dictionary of protein secondary structure, pattern recognition of hydrogen-bonded and geometrical features. Biopolymers 1983;22:2577-637

Kandala C, Kistler MK, Lawther RP, Kistler WS. Characterization of a genomic clone for rat seminal vesicle secretory protein IV. Nucleic Acids Res 1983;11:3169-86

Kelly SM, Jess TJ, Price NC. How to study proteins by circular dichroism. Biochim Biophys Acta 2005;1751:119-39

Laskowski RA. SURFNET, a program for visualizing molecular surfaces, cavities, and intermolecular interactions. J Mol Graph 1995;13:323-30

Latello ZS, Hall JA. Reaction of thrombins with human antithrombin III. I. Enzyme activity losses unrelated to the inhibitory reaction and their prevention. Thrombosis Research 1986;43:507-21

\section{Laemmli UK. Nature 1970;47:680-5}

Li W, Johnson DJ, Esmon CT, Huntington JA Structure of the antithrombin-thrombin-heparin ternary complex reveals the antithrombotic mechanism of heparin. Nat Struct Mol Biol 2004;11:857-62

Lwaleed BA, Greenfield R, Stewart S, Birch B, Cooper AJ. Seminal clotting and fibrinolytic balance, a possible physiological role in the male reproductive system. Thromb Haemost 2004;92:752-66

Mancuso F, Calignano A, Cozzolino A, Metafora S, Porta R. Inhibition of zymosan-induced air-pouch inflammation by rat seminal vesicle protein and by its spermidine derivative. Eur J Pharmacol 1996;312:327-32

Mansson PE, Sugino A, Harris SE. Use of a cloned double stranded cDNA coding for a major androgen dependent protein in rat seminal vesicle secretion, the effect of testosterone in gene expression. Nucleic Acids Res 1981; 9:935-46

McDonald C, Williams L, McTurck P, Fuller F, Mclntosh E, Higgins $S$. Isolation and characterisation of genes for androgen-responsive secretory proteins of rat seminal vesicles. Nucleic Acids Res 1983;11:917-30

Metafora S, Facchiano F, Facchiano A, Esposito C, Peluso G, Porta R. Homology between rabbit uteroglobin and the rat seminal vesicle sperm binding protein, prediction of structural features of glutamine substrates for transglutaminase. J Protein Chem 1987a;6:353-9

Metafora S, Peluso G, Ravagnan G, Gentile V, Fusco A, Porta R. Morphological Basis of Human Reproductive Function. (Spera G and De Kretzer DM; eds.), 1987b, 187-96, Plenum Press, New York and London

Metafora S, Peluso G, Persico P, Ravagnan G, Esposito C, Porta R. Immunosuppressive and anti-inflammatory properties of a major protein secreted from the epithelium of the rat seminal vesicles. Biochem Pharmacol 1989a;38:121-31

Metafora S, Porta R, Ravagnan G, Peluso G, Tufano MA, De Martino L, lanniello R, Galdiero F. Inhibitory effect of SV-IV, a major protein secreted from the rat seminal vesicle epithelium, on phagocytosis and chemotaxis of human polymorphonuclear leukocytes. J Leukocyte Biol 1989b;46: 409-16

Olson ST, Bjork I and Shore JD. Kinetic characterization of heparin-catalyzed and uncatalyzed inhibition of blood coagulation proteinases by antithrombin. Methods in Enzymology 1993;22:524-59

Ostrowski MC, Kistler MK, Kistler WS. Purification and cell-free synthesis of a major protein from rat seminal vesicle secretion. A potential marker for androgen action. J Biol Chem 1979;254:383-90

Pan YC, Li SS. Structure of secretory protein IV from rat seminal vesicles. Int J Pept Prot Res 1982;20:177-87

Pavonessa G, Metafora S, Tajana GF, Abrescia P, De Santis A, Gentile V, Porta R. Transglutaminase-mediated modifications of the rat sperm surface in vitro. Science 1984; 226:852-5

Peluso G, Porta R, Esposito C, Tufano MA, Toraldo R, Vuotto $M L$, Ravagnan G, Metafora S. Suppression of rat epididymal sperm immunogenicity by a seminal vesicle secretory protein and transglutaminase both in vivo and in vitro. Biol Reprod 1994;50:593-602

Romano-Carratelli C, Galdiero M, Nuzzo I, Bentivoglio C, Porta R, Peluso G, Ravagnan G, Metafora S. In vivo inhibition of cell-mediated and humoral immune responses to cellular antigens by SV-IV, a major protein secreted from the rat seminal vesicle epithelium. J Reprod Immunol 1995;28: $15-30$

Stiuso P, Metafora S, Facchiano AM, Colonna G, Ragone R. The self-association of protein SV-IV and its possible functional implications. Eur J Biochem 1999;266:1029-35

Stubbs MT, Oschkinat H, Mayr I, Huber R, Angliker H, Stone $\mathrm{SR}$, Bode W. The interaction of thrombin with fibrinogen. A structural basis for its specificity. Eur J Biochem 1992; 206:187-95

Tufano MA, Porta R, Farzati B, Di Pierro P, Rossano F, Catalanotti P, Baroni A, Metafora S. Rat seminal vesicle protein SV-IV and its transglutaminase-synthesized polyaminated derivative SPD2-SV-IV induce cytokine release from human resting lymphocytes and monocytes in vitro. Cell Immunol 1996;168:148-57

Vuotto ML, Peluso G, Mancino D, Colonna G, Facchiano A lelpo MT, Ravagnan G, Metafora S. Inhibition of interleukin-1 release and activity by the rat seminal vesicle protein SV-IV. J Leukocyte Biol 1993;53:214-22 